\title{
Sarcoidosis as an Autoimmune Disease
}

\author{
Anna A. Starshinova ${ }^{1 *}$, Anna M. Malkova ${ }^{1}$, Natalia Y. Basantsova ${ }^{1,2}$, Yulia S. Zinchenko ${ }^{1,2}$, \\ Igor V. Kudryavtsev ${ }^{1,3,4}$, Gennadiy A. Ershov ${ }^{1}$, Lidia A. Soprun ${ }^{1}$, Vera A. Mayevskaya ${ }^{5}$, \\ Leonid P. Churilov ${ }^{1,2}$ and Piotr K. Yablonskiy ${ }^{1,2}$ \\ ${ }^{1}$ Laboratory of the Mosaic of Autoimmunity, St. Petersburg State University, St. Petersburg, Russia, ${ }^{2}$ Phthisiopulmonology \\ Department, St. Petersburg State Research Institute of Phthisiopulmonology, St. Petersburg, Russia, ${ }^{3}$ Immunology \\ Department, Institute of Experimental Medicine, St. Petersburg, Russia, ${ }^{4}$ Immunology Department, School of Biomedicine, \\ Far Eastern Federal University, Vladivostok, Russia, ${ }^{5}$ Foreign Languages Department, St. Petersburg University of \\ Economics, St. Petersburg, Russia
}

Despite the large number of performed studies, the etiology and pathogenesis of sarcoidosis still remain unknown. Most researchers allude to the possible autoimmune or immune-mediated genesis of the disease. This review attempts an integral analysis of currently available information suggesting an autoimmune genesis of sarcoidosis and is divided into four categories: the evaluation of clinical signs described both in patients with sarcoidosis and "classic" autoimmune diseases, the role of triggering factors in the development of sarcoidosis, the presence of immunogenic susceptibility in the development of the disease, and the analysis of cellular and humoral immune responses in sarcoidosis. Studying the etiology and pathogenesis of sarcoidosis will improve diagnostic procedures as well as the prognosis and patients' quality of life.

Keywords: sarcoidosis, autoimmune diseases, triggering factors, connective tissue diseases, HLA genotype

\section{INTRODUCTION}

Sarcoidosis is a multisystem granulomatous disease of unknown origin with predominant lung involvement, variable clinical course, and no universally accepted treatment algorithm $(1,2)$. The disease occurs worldwide, varying in prevalence and clinical course between regions, and populations. African Americans and Northern Europeans are considered to be the most susceptible to the development of sarcoidosis with the predominance being in women, and incidence peaks from 30 to 60 years of age (2).

Recently, much attention has been paid to the study of the etiology and pathogenesis of sarcoidosis and the role of autoimmunity in its development and progression. In addition to genetic predisposition, triggers such as infection, inorganic materials, and environmental factors are likely to play a role, which leads to the possible development of an autoimmune response in the disease $(2,3)$.

Sarcoidosis has a wide variety of clinical phenotypes wherein many of them remind "classic" autoimmune diseases. About half of the patients have no symptoms, while in severe clinical cases, sarcoidosis can lead to a failure of the internal organ functions with the development of fibrosis and pulmonary hypertension. The most common clinical symptoms of pulmonary sarcoidosis are a dry cough, shortness of breath, and chest pain, which are described in more than $50 \%$ of patients. Up to $30 \%$ of cases include fever, unexplained weight loss, and chronic fatigue $(1,2)$. Extrapulmonary manifestations of the disease are described in $15-25 \%$ of cases. The most common are arthralgia, arthritis, periarthritis, acute nodular myositis, and chronic 
myopathy, where differential diagnosis is made with rheumatoid arthritis and other connective tissue disorders. Two main acute syndromes in sarcoidosis are described: Löfgren's syndrome manifested by nodular erythema, fever, polyarthritis, and uveitis and Heerfordt syndrome, which is described as a combination of uveitis, parotitis, fever, and facial paralysis $(2,4)$.

Pulmonary sarcoidosis may coexist with other autoimmune diseases, which suggests the possibility of a common pathogenesis and genetic predisposition. Most often, cases of sarcoidosis associated with Sjogren's syndrome are described, where patients have signs of both diseases, e.g., epithelioid granulomas in their internal organs as well as anti-Ro and anti-La autoantibodies as well as lacrimal and salivary gland dysfunction. Sarcoidosis and Sjogren's syndrome are both associated with the HLA-DR3 genotype and elevated levels of CD4+ lymphocytes $(5,6)$.

In some cases, a combination of systemic lupus erythematosus (SLE) and sarcoidosis is observed. As a rule, SLE debuts as a primary disease where over time non-caseating granulomas in the skin and lungs are detected (7). These cases suggest a common pathogenesis of both sarcoidosis and SLE regarding the similarity of some laboratory findings: In both diseases antinuclear antibodies (in sarcoidosis up to $30 \%$ of cases), a disturbance of the $\mathrm{T}$ and $\mathrm{B}$ lymphocytes ratio, and the elevation of immunoglobulin concentration are observed.

The combination of sarcoidosis with Crohn's disease, antiphospholipid syndrome, idiopathic pulmonary fibrosis, and primary biliary cirrhosis is also described (8). When sarcoidosis coexists with ankylosing spondylitis, non-caseating granulomas in the lungs, sacroiliitis, and the HLA-B27 genotype typical for spondyloarthritis are described (9).

One of the most important evidence of the autoimmune inflammation in sarcoidosis is the formation of granulomas, mainly in the lungs and the mediastinal lymph nodes as well as in the skin and liver of patients. The formation of granulomas of both infectious and autoimmune nature is based on the aggregation of hypertrophic macrophages. In infectious granulomatosis, such as tuberculosis, a pronounced activation of Th1 lymphocytes and M1 macrophages which then progress to the M2 phenotype is described. In sarcoidosis the opposite situation is observed: the M2 (anti-inflammatory) macrophage phenotype predominates in granulomas, which represents paradoxically reduced immune response. When studying the molecular mechanisms underlying the dysfunction of macrophages, there is growing evidence of the role of the mTOR pathway in granuloma formation. Linke and Wilson et al. in their studies showed that activation of rapamycin (mTOR) complex 1 (mTORC1) in macrophages in mice leads to the progression and development of granulomas. It has also been shown in people with a progressive sarcoidosis $(10,11)$.

After processing of environmental immunogenic antigens by mononuclear antigen-presenting cells, the antigen is presented to T-effector cells. Further activation of immune cells occurs with the help of various chemokines, such as CCL5 (for Tx1) and CCL2 (for Tx2). Recently, a lot of attention has been paid to the role of T17 lymphocytes in the pathogenesis of sarcoidosis, a subgroup of CD4+ lymphocytes expressing IL-17A, which exhibit pro-inflammatory or anti-inflammatory properties in response to the local inflammatory milieu. It has been shown that in sarcoidosis granuloma macrophages express CCR20, causing the attraction of Tx17, and the expression of IL-23 causes a significant increase in the concentration of $\operatorname{IL}-17 \mathrm{~A}(11,12)$. The ratio between Th17 and Treg cells probably determines the development and clinical course of sarcoidosis and can serve as a prognostic marker. Its increase indicates active sarcoidosis and correlates with the likelihood of exacerbation when steroid therapy is canceled (12).

Considering the possible autoimmune nature of sarcoidosis, it is necessary to discuss the possibilities of treatment with immunosuppressive therapy. Corticosteroids for patients with sarcoidosis are considered as the treatment of choice despite many possible contraindications and side effects $(13,14)$. If the corticosteroid therapy is ineffective and the disease progresses, the use of cytostatics (methotrexate, leflunomide, azathioprine) is recommended, but the doses and duration of treatment in patients with sarcoidosis require further study (15). In chronic sarcoidosis, especially in patients with extrapulmonary lesions, the use of TNF- $\alpha$ inhibitors (infliximab, adelemaumab, rituximab) is possible, though this question requires further study due to the immunologic abnormalities that accompany this kind of treatment and the uneven role of TNF- $\alpha$ in granuloma formation (16). Other biotherapy options for sarcoidosis are also being explored. The efficacy of a therapy based on inhaled vasoactive intestinal peptide (IVIP) has been shown. IVIP increases the activity of regulatory $\mathrm{T}$ cells and decreases the activity of effector $\mathrm{T}$ cells, thereby providing an immunoregulatory effect (17). There are studies on the possible beneficial effect of using IL-6 suppressors. The level of this cytokine is increased in patients with sarcoidosis and correlates with the level of CD3+ lymphocytes (tocilizumab), cytotoxic Tlymphocyte (abetacept), and IL-12/IL-23P40 and Th17 pathways, inducing the production of $\mathrm{TNF} \alpha$ (ustekinumab, tildrakizumab, secukinumab) (18). The effectiveness of immunosuppressive therapy in the treatment of patients with sarcoidosis alludes to the important role of the autoimmune component in the pathogenesis of this disease.

Despite a large number of studies on sarcoidosis, its etiology is still not fully understood. To consider the possible autoimmune nature of sarcoidosis, the criteria proposed in 1993 by N.R. Rose and C. Bona can be used (19). In accordance with the classification, direct proof, indirect and circumstantial evidence are distinguished. Direct criteria include: the occurrence of the disease in a healthy individual (human or animal) with the injection of purified human antibodies, including during transplacental transfer, or in vitro destruction of cells carrying specific antigen. Indirect evidence includes detection of the corresponding antigen in humans or its equivalent in animals and reproduction of essential features of the disease by immunization. Circumstantial evidence includes association with other autoimmune diseases, lymphocytic infiltration, statistical 
association with specific HLA haplotype, and positive response to immunosuppression.

To assess sarcoidosis compliance with autoimmune disease criteria, a detailed study of risk factors, environmental, immunological, and immunogenetic triggers is necessary. Review and original articles from 1960 to 2019 were studied in the international databases (PubMed, Web of Science, SCOPUS, Elsevier, ScienceDirect). The search was performed with keywords: Sarcoidosis, autoimmune reactions, autoimmunity, antibodies, and HLA genotype.

\section{THE ETIOLOGICAL FACTORS IN THE DEVELOPMENT OF SARCOIDOSIS: THE ROLE OF INFECTIOUS AGENTS AS A TRIGGER FACTOR}

Identifying the etiological factor in order to improve diagnosis and treatment in sarcoidosis is a very important problem (19). Numerous studies are targeting on the identification of an infectious agent that can be a trigger for sarcoidosis. Different bacteria, fungi, and viruses that can cause the formation of granulomas are described in patients with sarcoidosis $(20,21)$. The role of Mycobacterium tuberculosis and Propionibacterium acnes are most widely studied $(22,23)$. Particular attention is paid to the infection of $M$. tuberculosis, its role in the development of sarcoidosis since the 1960s has been observed by clinicians. One of the first papers tackling the effect of $M$. tuberculosis on the development of sarcoidosis is the study of clinical cases in which the association of a previous tuberculosis infection with the subsequent development of sarcoidosis is shown. According to the data described, treatment with antiTB drugs was not effective, while the use of corticosteroids led to a decrease in granulomas and the reduction of clinical symptoms (24).

With the development of molecular genetic methods, it became possible to identify specific markers of $M$. tuberculosis. Since the 1980s the presence of mycobacterial genetic material in patients with sarcoidosis was studied, according to which M. tuberculosis DNA or RNA was detected in $20-50 \%$ of cases (22). Serological methods for confirming the association of mycobacterial infection and the development of sarcoidosis originate from the 1990s with studies of the cross-reactions of bacterial antigens with patient serum. Antibodies to mycobacterial proteins $\mathrm{p} 36$, heat shock proteins hsp 65 and hsp70 were found in sarcoidosis patients (25). Studies by Ang et al. have shown a cross-reaction of mycobacterial antigens with cytoskeleton proteins of Schaumann bodies (tubulin, desmin, vimentin) (26). Activation of a cytotoxic cellular response in peripheral mononuclear cells of patients with sarcoidosis in response to $M$. tuberculosis specific antigens has been shown during incubation of mononuclear cells with ESAT-6 and KATG proteins $(24,27)$.

The possible evidence of the role of $M$. tuberculosis in the pathogenesis of sarcoidosis might be shown with the studies on animal models. The development of sarcoid granulomas was shown by Chen et al. in an experiment with Lewis rats and
C57BL/6 mice. The formation of granulomas was described after the injection of cell lysates and recombinant catalase of $M$. tuberculosis (28). Later, Swaisgood et al. investigated the role of mycobacterial superoxide dismutase A in C57BL/6 mice where the development of granulomas and increased concentrations of CD4+ cells, IL-2, and IFN- $\gamma$ in bronoalveolar lavage were shown (29).

Given the possible role of $P$. acnes, Werner et al. performed an experiment on the C57BL/6 mice, where the live strain of the microorganism isolated from the respiratory tract of a sarcoidosis patients was injected. After several days, the formation of granulomas and an increase in IFN- $\gamma$ producing CD4+ cells were detected in animal tissues, while the size of granulomas was more significant than in experiments with heat-killed strains (30). The main issue of these models is the question of specificity and chronicity of granuloma formation. Because the results of these studies were contradictory, and there is no consensus among researchers about the exact relationship between the role of the infectious agent in the development of sarcoid granulomas, further studies are required (31).

The role of fungi in the development of sarcoidosis was studied by examining office staff working in old buildings. A tendency for an increase in the incidence of sarcoidosis and the presence of fungi in the dust was noted (32, 33). There are no studies showing the direct effect of infectious agents on the development of granulomas in humans. An important counterargument is also the absence of microorganisms in granulomas.

\section{THE ROLE OF INORGANIC DUST AND OTHER EXOGENOUS TRIGGERS IN SARCOIDOSIS}

Among the chemicals which may be a triggering factor in patients with sarcoidosis, silicone holds a special place (34). This material, being considered biologically inert, is widely used in breast implants, artificial joints, shunts for patients with hydrocephalus, and catheters. It has been shown that in predisposed patients, at the site of its administration, giant cell granulomas containing silicone particles may form, and the specific clinical symptoms may be observed $(34,35)$. When silicone implants are removed, the described changes regress in $60-80 \%$ of cases (34).

A recent study by A. Watad comparing 24,651 patients with silicone implants and 98,604 patients without foreign bodies showed an increased risk of autoimmune diseases (OR 1.21, 95\% CI 1.17-1.26), the most pronounced associations being with sarcoidosis, Sjogren's syndrome, and systemic scleroderma after silicone implantation (34). These cases demonstrate the role of silicone as an adjuvant in the progression of sarcoidosis with the development of both focal (the appearance of sarcoid granulomas in the skin at the site of silicone mammoplasty or subcutaneous injections), and most importantly, systemic manifestations of sarcoidosis $(8,35)$.

One of the possible triggering factors that increases the incidence of sarcoidosis is inorganic dust. In epidemiological 
studies, the mechanism and specific components of dust causing granuloma formation were not demonstrated, however, an increase in the incidence of sarcoidosis after the collapse of the World Trade Center on September 11, 2001 was recorded $(36,37)$. When studying the composition of inorganic dust that appeared after the collapse of the Center, it was found that it consisted mainly of concrete components, including gypsum, anhydrite (anhydrous calcium sulfate), and fiberglass. The obtained data suggested the effect of inorganic triggers of sarcoidosis (silicates, talc, and others), which were described earlier in a number of clinical cases as causal factors of sarcoidosis development $(35,37)$.

There is some evidence in scientific literature of the effect of printer or copier toner ink on the development of sarcoidosis. For example, Armbruster et al. described a 39-year-old non-smoker who, after 18 months working at a newspaper agency, had intrathoracic lymphadenopathy and disseminated changes in the lungs (38). Histological biopsy examination of the lungs and lymph nodes revealed epithelioid cell granulomas without caseous necrosis; an additional examination of the obtained tissues revealed toner dust microparticles. Although granulomatous pneumonitis with mediastinum lymphadenopathy was diagnosed due to copy machine emissions, the patient most likely suffered from pulmonary sarcoidosis of the lungs and intrathoracic lymph nodes. Given the likely multifactorial nature of sarcoidosis and the role of various adjuvants acting as triggers for the development of the disease, the impact of such a multicomponent substance as ink in printer toner or copier, especially with longterm and direct use, can be considered as one of the adjuvants for sarcoidosis. The toner particles diameter is from 2 to $10 \mu$, when inhaled, they are deposited mainly in the tracheobronchial and alveolar regions. Toners are composed of thermoplastic polymer particles, usually styrene-acrylate copolymer, which are fixed on the paper by melting. Black toners contain carbon black or iron oxide as pigments, and organic pigments are included in colored toners (38). In addition, toners contain additives such as wax and silicate, whose "positive" effect on the development of sarcoidosis has been considered many times before.

Thus, numerous studies including epidemiological analysis, in vitro experiments, experiments on animal models, and clinical observations have shown the role of environmental factors (silicates, insecticides, silicone, etc.), infectious agents (Propionibacterium acnes, M. tuberculosis, and fungi) in the development of sarcoidosis. These factors can play an important role in the development of the disease (39).

\section{THE ROLE OF VIMENTIN AS AN AUTOANTIGEN IN SARCOIDOSIS}

The role of vimentin-a peptide presented in the cells of the connective tissue, which is involved in intercellular interactions and functioning of the immune system, has been known for a long time in the development of autoimmune diseases. Recent studies suggest that the mesenchymal protein vimentin, may be an autoantigen for sarcoidosis. The presence of autoantibodies to this protein is described in the pathogenesis of rheumatoid arthritis, systemic lupus erythematosus, and many other systemic autoimmune diseases $(40,41)$.

The first mention of vimentin in sarcoidosis was made when studying the asteroid bodies of the giant multinucleated cells in granulomas. The researchers discovered that asteroid bodies consisted of vimentin filaments and were the result of an aggregation of filamentous and microtubular systems of the centrospheres, which might be due to local liquid shifts, and solgel transformations. The authors suggested that such changes in the structure of giant cells could lead to their dysfunction and exhaustion, which might play an important role in granuloma development (42).

A possible relationship between vimentin and sarcoidosis development was shown in the study on the cross-reaction of antimycobacterial antibodies with Schaumann body proteins in giant sarcoid granuloma cells. Granulomas showed the highest intensity for lysosomal proteins of muramidase (muramidase proteins) and CD68, which was different for some cytoskeleton proteins (tubulin, desmin, vimentin) (26).

Despite the fact of elevated levels of vimentin in granulomas, for a long time there was no evidence of an autoimmune response against this protein. Since 2007, the Wahlström group has studied cellular and humoral response in sarcoidosis and detected specific T-cells and antibodies to vimentin in representatives of the HLA-DR-B1*0301 genotype (43). The role of vimentin in the pathogenesis of sarcoidosis was shown in Eberhardt's studies of Tcell response in the incubation of mononuclear cells with Kveim and vimentin reagent (44).

Despite the data obtained, it is difficult to state whether vimentin is an autoantigen in sarcoidosis. To confirm this hypothesis it is necessary to identify autoantibodies to vimentin, establish the cytotoxicity of vimentin-specific $\mathrm{T}$ and $\mathrm{B}$ cells against tissues, and also obtain a model of the disease in animals by injection of vimentin protein. This requires further study.

\section{IMMUNOGENETICS OF SARCOIDOSIS: A BRIEF SYNOPSIS OF AUTOIMMUNE DISORDERS IN SARCOIDOSIS}

The immunogenetic features of autoimmune pathologies include their relationship with the HLA genotypes. The HLA genotypes are associated with many autoimmune diseases, which enabled us to use genotyping of their loci to determine susceptibility to certain diseases, the nature of the disease course, and the effectiveness of treatment (45).

The MHC class I molecules (A, B, C) are presented on the membrane surfaces of all cell types, with the exception of trophoblast cells, and present antigens localized in the cells' cytosol of T lymphocytes. The MHC class II molecules (DQ, $\mathrm{DR}, \mathrm{DP}$ ) are predominantly expressed in the antigen-presenting cells, which represent antigens absorbed from the extracellular space by endocytosis. Presentation of the body's own antigens in association with MHC I or MHC II and their subsequent recognition by autoreactive cytotoxic $\mathrm{T}$ lymphocytes or T-helper 
cells, respectively, is a key mechanism for triggering autoimmune reactions (46).

Many characteristic HLA genes were found in sarcoidosis that encoded both molecules of the class I (some isoforms of HLA-A and -B) and class II (some of the isoforms of HLA are DPB1, -DQB1, -DRB1, -DRB3). Specific HLA genotypes have been identified for the various forms of the disease, the spectrum of the affected organs, as well as ethnic characteristics. For example, it was shown that carriers of the HLA-DRB1*04/*15 alleles are more likely to develop cardiovascular sarcoidosis, and the HLA-DRB1*04 alleles are more likely to develop uveitis (47). The HLA-DRB1*03 and HLA-DQB1*0201 alleles are associated with the development of Löfgren's syndrome, while the HLA-DRB1*15 and HLA-DQB1*0601 alleles are associated with chronic sarcoidosis, which is reflected in more detail in Table 1.

Among different ethnic groups most often affected by sarcoidosis-African Americans and Europeans-various HLA genotypes were found. The presence of HLA-DRB1*11:01 increased the risk of disease in both ethnic groups, whereas HLA$\mathrm{DRB}^{*}$ 12: 01/15: 03 was more common for African Americans, HLA-DRB1*15: 01 / 04:01-for the Caucasian race $(50,53)$. At the same time, the HLA-DRB1*03: 01 genotype for Europeans is a predisposing factor for the development of sarcoidosis, while for African Americans this genotype is of a protective value (48).

The class III of HLA genes was shown to be associated with sarcoidosis of the following genes: BTNL2, C4, C6orf10, HSPA1L, LTA, NOTCH4, TAP2, TNF, and VEGF. These genes are involved in many cellular processes and play a large role in all stages of inflammation. For example, the

TABLE 1 | Genotypes affecting the development and severity of sarcoidosis (41-45).

\begin{tabular}{|c|c|c|}
\hline References & HLA genotypes & $\begin{array}{l}\text { Discovered relationship } \\
\text { with various sarcoidosis } \\
\text { manifestations }\end{array}$ \\
\hline \multirow[t]{2}{*}{$\begin{array}{l}\text { Bogunia-Kubik } \\
\text { et al. (48) }\end{array}$} & HLA-DRB1*03 & $\begin{array}{l}\text { Favorable prognosis, acute } \\
\text { course }\end{array}$ \\
\hline & DRB1*15 & Chronic course \\
\hline \multirow[t]{2}{*}{ Planck et al. (49) } & DQB1*0201 & $\begin{array}{l}\text { Favorable prognosis, acute } \\
\text { course }\end{array}$ \\
\hline & DQB1*0602 & Chronic course \\
\hline $\begin{array}{l}\text { Foley et al. (50) } \\
\text { Kishore and } \\
\text { Petrek }(39,51) \\
\text { Fingerlin et al. (52) }\end{array}$ & $\begin{array}{l}\text { HLA-DRB1*01/04 } \\
\text { HLA-B08 } \\
\text { HLA-DRB1*03:01 }\end{array}$ & $\begin{array}{l}\text { Löfgren's syndrome, acute } \\
\text { course }\end{array}$ \\
\hline Moller et al. (20) & $\begin{array}{l}\text { HLA-DRB1 }{ }^{*} 12 / 14 \\
\text { HLA-DRB1 }{ }^{*} 14: 01 \\
\text { HLA-DRB1 } 1^{*} 04 / 15\end{array}$ & $\begin{array}{l}\text { Chronic course } \\
\text { Extrapulmonary lesions }\end{array}$ \\
\hline \multirow[t]{2}{*}{$\begin{array}{l}\text { Grunewald et al. } \\
\text { (47) }\end{array}$} & $\begin{array}{l}\text { DRB1 }{ }^{*} 07 \\
\text { DRB1 } 1^{*} 14 \\
\text { DRB1 }{ }^{*} 15\end{array}$ & $\begin{array}{l}\text { Chronic course, poor } \\
\text { prognosis }\end{array}$ \\
\hline & $\begin{array}{l}\text { DRB } 1^{*} 01 \\
\text { DRB } 1{ }^{*} 03\end{array}$ & $\begin{array}{l}\text { Löfgren's syndrome, good } \\
\text { prognosis }\end{array}$ \\
\hline
\end{tabular}

products of the NOTCH4 gene are Notch family proteins that control cell division during growth, differentiation, apoptosis and regulate $\mathrm{T}$-cell immune response. It was found that the NOTCH4 gene is associated with the development of other autoimmune diseases (systemic sclerosis, neonatal lupus, multiple sclerosis). The role of this gene in the pathogenesis of sarcoidosis is not yet known, but its relationship with sarcoidosis among African Americans, and Europeans has been shown (54).

The described immunological and immunogenetic disorders do not arise independently, but under the influence of certain triggering factors that activate and trigger the pathogenesis mechanism of the autoimmune response. Currently, this relationship is described in many studies.

\section{IMMUNOPATHOGENESIS OF SARCOIDOSIS: CHARACTERISTIC OF AUTOIMMUNE DISEASES IN PATIENTS WITH SARCOIDOSIS}

The main role in the pathogenesis of autoimmune diseases is played by T-cell immunity represented by the 1,2, 17 Th subtype of T helpers, regulatory T-cells, and also T-killers. It is believed that disturbance of the Th17 ratio stimulates the $\mathrm{T}$ regulatory cells, which play a role as suppressors of immune responses, and can lead to autoimmune inflammation characterized by the presence of autoantigen-specific $\mathrm{T}$ and $\mathrm{B}$ lymphocytes producing autoantibodies (55).

In various studies on sarcoidosis, disturbances were found in T-cell and B-cell immune responses. It is believed that the triggering factor for inflammation development in sarcoidosis is the contact of the foreign antigen with antigen-presenting cells leading to activation of $\mathrm{T}$ and $\mathrm{B}$ lymphocytes, which migrate to the inflammatory foci. It is observed, that due to the long persistence of the antigen, macrophages undergo epithelioid differentiation, lymphocytes constantly migrate to the center, thus, granulomas are formed $(56,57)$.

Considering that lymphocytes play the main role in granuloma formation, it can be said that the disturbance of cellular and humoral immune response is observed in sarcoidosis.

\section{CELLULAR IMMUNE RESPONSE}

As has been noted above, a distinctive feature of sarcoidosis is the formation of non-caseous granulomas, which include various immune competent cells. Thus, in the central part of such granulomas, macrophages or multinucleated giant cells and $\mathrm{CD} 3+\mathrm{CD} 4+\mathrm{T}$-helpers predominate as a result of their fusion, whereas cytotoxic CD3+ CD8+ T-lymphocytes, regulatory $\mathrm{T}$-cells, fibroblasts, and B-lymphocytes predominate in the peripheral part of the granulomas $(56,57)$. The leading role of tissue macrophages in the formation of granulomas in sarcoidosis was brought to light in the socalled "Th1-paradigm" of immunopathogenesis of this disease, 
which was based on the leading role of IFN $\gamma$ and T-helper type 1 as the main producers of this cytokine indispensable for the activation of macrophages to induce and maintain inflammatory processes in tissues during chronic activation of macrophages (58).

This circumstance allowed us to treat sarcoidosis primarily as an infectious disease. However, the description of a fundamentally new population of T-helper cells-T-helper 17 (Th17) as well as its separate highly specialized subtypeTh1/Th17 or Th17.1 cells capable of producing both IFN $\gamma$ and IL-17A at the same time, suggests the autoimmune nature of the disease $(58,59)$. Furthermore, in a number of studies, an increase in the level of Th17.1 and the proinflammatory cytokines produced by them in the peripheral blood and the composition of the bronchoalveolar lavage (BAL) fluid of patients with sarcoidosis was detected. An increase in the level of these cells, both at the systemic level (in the peripheral blood) and directly in the focus of the inflammatory reaction and damage to surrounding tissues was observed in a wide range of other systemic - for example, Sjögren syndrome and rheumatoid arthritis, and organ-specific- for example, type 1 diabetes mellitus and Crohn's disease (59).

In patients with sarcoidosis, an increase in Th17 was found in the peripheral blood and BAL, while the number of T regulatory cells in BAL was reduced and increased in the peripheral blood (60). Also, in many studies there was a decrease in the level of transcription factor T-regs FOXP3 in BAL, which indicates a decrease in cell function. Since Th17 contributes to fibrosis, and T-regs reveal anti-proliferative activity, the variability of their ratios may explain an increased proliferation of connective tissue in the affected organ as well as being one of the confirming factors of the autoimmune nature of sarcoidosis $(61,62)$.

Cytotoxic T-lymphocytes, along with Th, effectively produce key pro-inflammatory cytokines (TNF $\alpha$ and IFN $\gamma$ ), ensuring their high concentration at the sites of granuloma formation, which activates macrophages and attracts additional cells from the circulation (63). At present, the involvement of CD3+ CD8+ lymphocytes is shown in the pathogenesis of various forms of arthritis, multiple sclerosis, type 1 diabetes mellitus, and many other autoimmune diseases $(64,65)$. However, the role of CD8+ T-lymphocytes in granuloma formation in sarcoidosis remains poorly studied, which does not prevent us from considering this cell population as a promising therapeutic target in the treatment of sarcoidosis.

One of the main criteria for autoimmune disease is the presence of auto-antigen-specific T-lymphocytes. In 2012, Ahmadzai et al. described in sarcoidosis the activation of the peripheral mononuclears followed by the release of various cytokines after stimulation with autoantigens (vimentin, lysyltRNA synthetase) (66). Later, in the Grunewald study, the presence of specific type $1 \mathrm{CD} 4+\mathrm{T}$-helpers of the 1st type with $\mathrm{V} \alpha 2.3 / \mathrm{V} \beta 22$ receptors interacting with HLA-DRB1* 03 proteins was detected (67). When studying the receptors, the protein structure was calculated, which coincides with the vimentin structure represented by antigen-presenting cells using HLADRB1*03 (68).

\section{HUMORAL IMMUNITY: ANTIBODY-MEDIATED REACTIONS IN SARCOIDOSIS}

The earliest studies on the immunological characteristics of sarcoidosis have shown that patients with sarcoidosis have a significantly higher number of B-cell activating factor (BAFF) and, correspondingly, Ig-producing B-cells in the lung tissues, while there are various ratios of B-cell types $(69,70)$. In BAL of patients with sarcoidosis, there was a decrease in the number of memory B-cells, an increase in the number of B-regulatory cells producing IL-10, and hypergammaglobulinemia correlating with an increase of immunoglobulins in the peripheral blood (71). The use of anti-B-cell therapy (antibodies against CD20, rituximab) in the treatment of sarcoidosis resulted in clinical improvement, which suggests the participation of both "naive" B-cells and memory B-cells in the pathogenesis of the disease $(72,73)$. Hypergammaglobulinemia has been shown in several studies, but the association with the severity of the disease was not detected (74). Although some authors consider that patients with sarcoidosis have normal levels of serum immunoglobulins, but applying histological methods in the analysis of the subpopulation composition of cells forming granulomas, the accumulation of B cells in the lungs' lesions was shown (70).

The earliest data on autoantibodies in sarcoidosis were based on the results obtained from the patients diagnosed with sarcoidosis and various chronic liver diseases, in whom antimitochondrial antibodies were identified. Similar results were obtained in 2005 when examining patients with sarcoidosis and primary biliary cirrhosis. The authors find it difficult to name the underlying cause of an autoimmune response because the presence of antimitochondrial antibodies is characteristic of autoimmune liver damage (75-77).

Since sarcoidosis combines with other autoimmune diseases, the Weinberg group analyzed the presence of anti-nuclear antibodies and autoantibodies to double-stranded DNA to determine whether these markers could be used as predictors of disease development, such as systemic lupus erythematosus. However, antinuclear antibodies were detected in only one third of the patients, whereas antibodies to double-stranded DNA were in two patients, and therefore, these serological markers are not diagnostically significant (78).

In 2014, the S. Kobak group began studying autoantibodies specific for rheumatoid arthritis in patients with sarcoidosis. Of the 42 patients with sarcoidosis, only seven had a higher concentration of the rheumatoid factor, two of them had antibodies to citrullinated cyclic peptides. The anti-nuclear antibodies were detected in 12 patients. However, due to the low specificity of the detected antibodies, these serological indicators cannot be used as biomarkers of sarcoidosis $(79,80)$.

In 2018, Johan Grunewald's group showed the possible association of vimentin as an autoantigen in the development of sarcoidosis and published an article about the presence of autoantibodies to vimentin in serum and bronchoalveolar fluid of patients with sarcoidosis. At the same time, association with the HLA-DRB1*03 genotype was revealed (81). 
Table 2 presents studies dealing with various types of autoantibodies detected in patients with sarcoidosis.

According to the data presented in Table 2, the various autoantibodies were evaluated in patients with sarcoidosis in $26.7 \%$ of cases with variability from 4.7 to $29.5 \%$.

\section{THE ROLE OF INNATE IMMUNITY AND AUTO-INFLAMMATION IN THE PATHOGENESIS OF SARCOIDOSIS}

According to the proposed model of sarcoidosis, the antigenpresenting cells (macrophages, dendritic cells and epithelial cells) are the first in the cascade of inflammatory reactions. It is believed that with prolonged contact of foreign antigens with the toll-like receptors of antigen-presenting cells, macrophage activation and epithelioid differentiation occur. Macrophages begin to synthesize pro-inflammatory cytokines such as nuclear factor (NF)-kB, TNF-a, IL-1, which leads to the activation of the acquired immune system. B-lymphocytes and T-lymphocytes actively migrate to the focus of inflammation. T-cells undergo differentiation into T-helpers of the 1 st, $2 \mathrm{nd}$, 17th type, and regulatory T-cells, depending on secreted cytokines. The inability to quickly and efficiently eliminate a foreign antigen leads to the formation of granulomas $(20,21)$. However, unlike the typical granulomatous process, macrophages in sarcoidosis begin to differentiate into M2 type, which have anti-inflammatory properties and contribute to the chronicity of the process

TABLE 2 | Detection of various autoantibodies in sarcoidosis (74-80).

\begin{tabular}{|c|c|c|c|}
\hline References & $\begin{array}{l}\text { Study, Number of } \\
\text { patients with } \\
\text { sarcoidosis }\end{array}$ & $\begin{array}{c}\text { Number of } \\
\text { patients } \\
\text { with } \\
\text { changes }\end{array}$ & $\begin{array}{l}\text { Detected } \\
\text { antibodies }\end{array}$ \\
\hline Maddrey et al. (75) & $\begin{array}{l}20 \text { patients with } \\
\text { sarcoidosis and chronic } \\
\text { liver damage }\end{array}$ & $\begin{array}{l}1 / 20 \\
5.0 \%\end{array}$ & $\begin{array}{l}\text { Antimitochondrial } \\
\text { antibodies }\end{array}$ \\
\hline Fagan et al. (76) & $\begin{array}{l}4 \text { patients with } \\
\text { sarcoidosis and liver } \\
\text { damage }\end{array}$ & $4 / 4$ & \\
\hline Stanca et al. (77) & $\begin{array}{l}\text { Clinical case: patient } \\
\text { with sarcoidosis and } \\
\text { primary biliary cirrhosis }\end{array}$ & $1 / 1$ & \\
\hline \multirow[t]{2}{*}{$\begin{array}{l}\text { Weinberg et al. } \\
\text { (78) }\end{array}$} & $\begin{array}{l}34 \text { patients with } \\
\text { sarcoidosis }\end{array}$ & $\begin{array}{l}10 / 34 \\
29.4 \%\end{array}$ & $\begin{array}{l}\text { Antinuclear } \\
\text { antibodies }\end{array}$ \\
\hline & & $\begin{array}{l}2 / 34 \\
5.8 \%\end{array}$ & $\begin{array}{l}\text { Antibodies to } \\
\text { double stranded } \\
\text { DNA }\end{array}$ \\
\hline \multirow[t]{2}{*}{$\begin{array}{l}\text { Kobak et al. } \\
(9,79,80)\end{array}$} & $\begin{array}{l}42 \text { patients with } \\
\text { sarcoidosis }\end{array}$ & $\begin{array}{l}2 / 42 \\
4.7 \%\end{array}$ & $\begin{array}{l}\text { Antibodies to } \\
\text { citrullinated cyclic } \\
\text { peptide }\end{array}$ \\
\hline & & $\begin{array}{c}7 / 42 \\
16.7 \%\end{array}$ & Rheumatoid factor \\
\hline Total six studies & $\begin{array}{l}101 \text { patients with } \\
\text { sarcoidosis }\end{array}$ & $\begin{array}{l}27 / 101 \\
(26.7 \%)\end{array}$ & - \\
\hline
\end{tabular}

and fibrosis due to the production of profibrotic chemokine CCL18 (82).

Autoinflammatory diseases are characterized by chronic systemic inflammation caused by activation of innate immunity (neutrophils, macrophages) and manifested in lesions mainly of the musculoskeletal system, skin, and mucous membranes (83). This group includes early-onset sarcoidosis, which occurs in children and is characterized by the formation of non-caseating granulomas in various organs. Most often, symmetric arthritis, dermatitis, uveitis and neuropathies can be found. However, with this type of sarcoidosis, the etiology of the disease is already identified and described as the presence of mutations in the CARD15 [caspase activation and recruitment domain (CARD) family, member 15] or NOD2 (nucleotide-binding oligomerization domain containing 2) gene (84).

As shown above, the development of sarcoidosis is associated with a large number of genes, in particular with class II HLA genes. Moreover, with sarcoidosis, autospecific $\mathrm{T}$ and $\mathrm{B}$ cells that produce various autoantibodies are found. These facts do not allow to suggest an exclusively auto-inflammatory theory of sarcoidosis. Perhaps sarcoidosis begins as an auto-inflammatory disease in which the activation of adaptive immunity occurs with the appearance of autospecific $\mathrm{T}$ and $\mathrm{B}$ cells that produce autoantibodies to a specific antigen (85).

\section{CONCLUSION}

According to the criteria for autoimmune diseases proposed by Rose and Bona (19), in sarcoidosis only circumstantial evidence of autoimmune inflammation is described:

- the presence of various autoantibodies in the blood of patients; - association with other autoimmune diseases (SLE, Sjogren's syndrome);

- association with the HLA genotype (HLA-DRB1, HLA-DQB1);

- lymphocytic organ infiltration (the presence of sarcoid granulomas);

- response to immunosuppressive therapy.

At present, there is lack of evidence on the possible autoantigen in sarcoidosis, which induces the formation of sarcoid granulomas, antibodies, and T-specific lymphocytes in animal models to confirm the autoimmune origin of sarcoidosis. Vimentin appears to be the most likely antigen, against which the Grunewald group has detected both antibodies and vimentin-specific T cells.

The data analyzed in the review suggest the presence of autoimmune/inflammatory syndrome induced by adjuvants described in 2011 by Shoenfeld and Agmon-Levin (86). The syndrome implies various autoimmune conditions that occur under the influence of various triggering factors in individuals with a certain immunogenetic predisposition, which trigger immunological reactions characteristic of autoimmune diseases.

The described major (clinical) and minor (immunogenetic) ASIA criteria enable us to assume the autoimmune nature of inflammation in sarcoidosis. Analyzing the 
proposed algorithms to detect autoimmune diseases, a unified approach to assess the possible autoimmune origin of sarcoidosis can be proposed: Identification of trigger factors affecting the development of sarcoidosis; evaluation of immunogenetic susceptibility to the development of the disease; analysis of the immunological features in sarcoidosis; analysis of the clinical features of autoimmune diseases.

The analysis of the current data does not exclude the autoinflammatory nature of the occurrence and development of sarcoidosis. Thus, setting the final point in the etiology and pathogenesis of the disease is not yet possible.

\section{REFERENCES}

1. Culver DA, Judson MA. New advances in the management of pulmonary sarcoidosis. BMJ. (2019) 367:15553. doi: 10.1136/bmj.15553

2. Grunevald G, Grutters JC, Arkema EV, Saketkoo LA, Moller DR, Müller-Quernheim J Sarcoidosis. Nat Rev. (2019) 5:45. doi: 10.1038/s41572-019-0096-x

3. Kaiser Y, Eklund A, Grunewald J. Moving target - shifting the focus to pulmonary sarcoidosis as an autoimmune spectrum disorder. Eur Respir J. (2019) 11:54. doi: 10.1183/13993003.021532018

4. Ungprasert P, Ryu JH, Matteson EL. Clinical manifestations, diagnosis, and treatment of sarcoidosis. Mayo Clin Proc Innov Qual Outcomes. (2019) 3:35875. doi: 10.1016/j.mayocpiqo.2019.04.006

5. Vitali C, Bombardieri S, Jonsson R, Moutsopoulos HM, Alexander EL, Carsons SE, et al. Classification criteria for Sjogren's syndrome: a revised version of the european criteria proposed by the american-european consensus group. J Ann Rheum Dis. (2002) 61:554-8. doi: 10.1136/ard.61.6.554

6. Santiago T, Santiago M, Rovisco J, Ferreira J, Duarte C, Malcata A, et al. Coexisting primary Sjögren's syndrome and sarcoidosis: coincidence, mutually exclusive conditions or syndrome? J Rheumatol Int. (2014) 34:161922. doi: 10.1007/s00296-014-3024-0

7. Wesemann DR, Costenbader KH, Coblyn JS. Co-existing sarcoidosis, systemic lupus erythematosus and the antiphospholipid antibody syndrome case reports and discussion from the brigham and women's hospital lupus center. J Lupus. (2009) 18:202-5. doi: 10.1177/0961203308100483

8. Kobak S. Sarcoidosis: a rheumatologist's perspective. J Adv Musculoskel. (2015) 7:196-205. doi: 10.1177/1759720X15591310

9. Kobak S, Sever F, Sivrikoz O, Karaarslan A. Coexistence of ankylosing spondylitis and löfgren's syndrome. Case Rep Rheumatol. (2014) 2014:747698. doi: 10.1155/2014/747698

10. Linke M, Pham HTT, Katholnig K, Schnoller T, Miller A, Demel F, et al. Chronic signaling via the metabolic checkpoint kinase mTORC1 induces macrophage granuloma formation and marks sarcoidosis progression. Nat Immunol. (2017) 18:293-302. doi: 10.1038/ni.3655

11. Wilson JL, Mayr HK, Weichhart T. Metabolic programming of macrophages: implications in the pathogenesis of granulomatous disease. Front Immunol. (2019) 10:2265. doi: 10.3389/fimmu.2019.02265

12. Crouser ED. Role of imbalance between Th17 and regulatory T-cells in sarcoidosis. Curr Opin Pulm Med. (2018) 24:5216. doi: 10.1097/MCP.0000000000000498

13. Baughman RP, Lower EE. Treatment of sarcoidosis. J Clinic Rev Allerg Immunol. (2015) 49:79-92. doi: 10.1007/s12016-015-8492-9

14. Grutters JC, van den Bosch JM. Corticosteroid treatment in sarcoidosis. Eur Resp J. (2006) 28:627-36. doi: 10.1183/09031936.06.00105805

15. Nagai S, Izumi T. Treatment With Methotrexate in Patients With Sarcoidosis. IntechOpen (2013), p. 427-33. doi: 10.5772/55042

16. Amber KT, Bloom R, Mrowietz U. TNF- $\alpha$ : a treatment target or cause of sarcoidosis? J Eur Acad Dermatol Venereol. (2015) 11:210411. doi: $10.1111 /$ jdv.13246

\section{AUTHOR CONTRIBUTIONS}

AS: main author. AM, NB, YZ, IK, GE, LS, and LC: analysis of literature. VM: text translation. PY: coordinator of the project.

\section{FUNDING}

This work was supported by grant from the Government of the Russian Federation (contract No. 14.W03.31.0009 dated February 13, 2017) on the allocation of grant for the state support of scientific researches conducted under the guidance of leading scientists.

17. Prasse A, Zissel G, Lützen N, Schupp J, Schmiedlin R, Gonzalez-Rey $\mathrm{E}$, et al. Inhaled vasoactive intestinal peptide exerts immunoregulatory effects in sarcoidosis. JAm J Respir Crit Care Med. (2010) 182:5408. doi: 10.1164/rccm.200909-1451OC

18. Jared Chiarchiaro, Bill B. Chena, Gibsona KF. New molecular targets for the treatment of sarcoidosis. Curr Opin Pulm Med. (2016) 22:51521. doi: 10.1097/MCP.0000000000000304

19. Rose NR, Bona C. Defining criteria for autoimmune diseases (witebsky's postulates revisited). Immunol Today. (1993) 14:42630. doi: 10.1016/0167-5699(93)90244-F

20. Moller DR, Rybicki BA, Hamzeh NY, Montgomery CG, Chen ES, Drake W, et al. Genetic, immunologic, and environmental basis of sarcoidosis. J Thorac. (2017)14:429-36. doi: 10.1513/AnnalsATS.201707-565OT

21. Loke WSJ, Herbert C, Thomas PS. Sarcoidosis: immunopathogenesis and immunological markers. Int J Chronic Dis. (2013) 2013:114. doi: $10.1155 / 2013 / 928601$

22. Gupta D, Agarwal R, Aggarwal AN, Jindal SK. Molecular evidence for the role of mycobacteria in sarcoidosis: a meta-analysis. Eur Respir J. (2007) 30:508-16. doi: 10.1183/09031936.00002607

23. Eishi Y. Etiologic aspect of sarcoidosis as an allergic endogenous infection caused by Propionibacterium acnes. Biomed Res Int. (2013) 93:5289 doi: 10.1155/2013/935289

24. Song Z, Marzilli L, Greenlee BM, Chen ES, Silver RF, Askin FB. Mycobacterial catalase-peroxidase is a tissue antigen and target of the adaptive immune response in system sarcoidosis. J Exp Med. (2005) 201:75567. doi: 10.1084/jem.20040429

25. Dubaniewicz A, Dubaniewicz-Wybieralska M, Sternau A, Zwolska Z, IzyckaSwieszewska E, Augustynowicz-Kopec E, et al. Mycobacterium tuberculosis complex and mycobacterial heat shock proteins in lymph node tissue from patients with pulmonary sarcoidosis. J Clin Microbiol. (2006) 44:344851. doi: 10.1128/JCM.01433-06

26. Ang SC, Moscovic EA. Cross-reactive and species specific mycobacterium tuberculosis antigens in the immunoprofile of Schaumann bodies: a major clue to the etiology of sarcoidosis. J Histol Histopathol. (1996) 11:125-34.

27. Drake WP, Dhason MS, Nadaf M, Shepherd BE, Vadivelu S, Hajizadeh $\mathrm{R}$, et al. Cellular recognition of mycobacterium tuberculosis esat- 6 and katg peptides in systemic sarcoidosis. Infect Immun. (2007) 75:52730. doi: 10.1128/IAI.00732-06

28. Chen ES, Song Z, Willett MH, Heine S, Yung RC, Liu MC, et al. Serum amyloid A regulates granulomatous inflammation in sarcoidosis through Tolllike receptor-2. Am J Respir Crit Care Med. (2010) 181:36073. doi: 10.1164/rccm.200905-0696OC

29. Swaisgood CM, Oswald-Richter K, Moeller SD, Klemenc JM, Ruple LM, Farver CF, et al. Development of a sarcoidosis murine lung granuloma model using Mycobacterium superoxide dismutase A peptide. Am J Respir Cell Mol Biol. (2011) 44:166-74. doi: 10.1165/rcmb.2009-0350OC

30. Werner JL, Escolero SG, Hewlett JT, Mak TN, Williams BP, Eishi Y, et al. Induction of pulmonary granuloma formation by propionibacterium acnes is regulated by MyD88 and Nox2. Am J Respir Cell Mol Biol. (2016) 56:121-30. doi: $10.1165 / \mathrm{rcmb} .2016-0035 \mathrm{OC}$ 
31. Hu Y, Yibrehu B, Zabini D, Kuebler WM. Animal models of sarcoidosis. Cell Tissue Res. (2017) 367:651-61. doi: 10.1007/s00441-016-2526-3

32. Terčelj M, Salobir B, Harlander M, Rylander R. Fungal exposure in homes of patients with sarcoidosis - an environmental exposure study. JEnviron Health. (2011) 10:8-12. doi: 10.1186/1476-069X-10-8

33. Terčelj M, Stopinšek S, Ihan A, Salobir B, Simčič S, Wraber B, et al. In vitro and in vivo reactivity to fungal cell wall agents in sarcoidosis. J Clin Exp Immunol. (2011) 166:87-93. doi: 10.1111/j.1365-2249.2011.04456.x

34. Watad A, Rosenberg V, Tiosano S. Silicone breast implants and the risk of autoimmune/rheumatic disorders: a real-world analysis. Int J Epidemiol. (2018) 47:1846-54. doi: 10.1093/ije/dyy217

35. Bindoli S, Dagan A, Torres-Ruiz JJ, Perricone C, Bizjak M, Doria A, et al. Sarcoidosis and autoimmunity: from genetic background to environmental factors. Isr Med Assoc J. (2016) 18:197-202.

36. Jordan HT, Stellman SD, Prezant D, Teirstein A, Osahan SS, Cone JE. Sarcoidosis diagnosed after september 11, 2001, among adults exposed to the world trade center disaster. J Occup Environ Med. (2011) 53:96674. doi: 10.1097/JOM.0b013e31822a3596

37. Bowers B, Hasni S, Gruber BL. Sarcoidosis in world trade center rescue workers presenting with rheumatologic manifestations. J Clin Rheumatol. (2010) 16:26-7. doi: 10.1097/RHU.0b013e3181c78856

38. Armburdsen C, Dekan G, Hovorka A. Granulomatous pneumonitis and mediastinal lymphadenopathy due to photocopier toner dust. Lancet. (1996) 348:690. doi: 10.1016/S0140-6736(05)65119-7

39. Kishore A, Petrek M. Immunogenetics of sarcoidosis. J Int Trends Immun. (2013) 1:43-53. doi: 10.1007/s12016-015-8477-8

40. Musaelyan A, Lapin S, Nazarov V, Tkachenko O, Gilburd B, Mazing A, et al. Vimentin as antigenic target in autoimmunity: a comprehensive review. $J$ Autoimmun Rev. (2018) 17:926-34. doi: 10.1016/j.autrev.2018.04.004

41. Valesini G, Gerardi MC, Iannuccelli C, Pacucci VA, Pendolino M, Shoenfeld Y. Review citrullination and autoimmunity. J Autoimmun Rev. (2015) 14:4907. doi: 10.1016/j.autrev.2015.01.013

42. Cain H, Kraus B. Immunofluorescence microscopic demonstration of vimentin filaments in asteroid bodies of sarcoidosis. A comparison with electron microscopic findings. J Virchows Arch B Cell Pathol Incl Mol Pathol. (1983) 42:213-26. doi: 10.1007/BF02890384

43. Wahlström J, Dengjel J, Persson B, Duyar H, Rammensee HG, Stevanovic $\mathrm{S}$, et al. Identification of HLA-DR-bound peptides presented by human bronchoalveolar lavage cells in sarcoidosis. J Clin Invest. (2007) 117:357682. doi: 10.1172/JCI32401

44. Eberhardt C, Thillai M, Parker R, Siddiqui N, Potiphar L, Goldin R, et al. Proteomic analysis of Kveim reagent identifies targets of cellular immunity in sarcoidosis. PLoS ONE. (2017) 12:e0170285. doi: 10.1371/journal.pone.0170285

45. Gough SCL, Simmonds MJ. The HLA region and autoimmune disease: associations and mechanisms of action. Curr Genomics. (2007) 8:45365. doi: 10.2174/138920207783591690

46. Choo SY. The HLA system: genetics, immunology, clinical testing, and clinical implications. Yonsei Med J. (2007) 48:11-23. doi: 10.3349/ymj.2007.48.1.11

47. Grunewald J, Eklund A, Olerup O. Human leukocyte antigen class I alleles and the disease course in sarcoidosis patients. Am J Respir Crit Care Med. (2004) 169:696-702. doi: 10.1164/rccm.200303-459OC

48. Bogunia-Kubik K, Tomeczko J, Suchnicki K, Lange A. HLA$\mathrm{DRB} 1 * 03, \quad \mathrm{DRB} 1 * 11$ or $\mathrm{DRB}^{*} 12$ and their respective DRB3 specificities in clinical variants of sarcoidosis. Tissue Antigens. (2001) 57:87-90. doi: 10.1034/j.1399-0039.2001.057001087.x

49. Planck A, Eklund A, Yamaguchi E, Grunewald J. Angiotensin-converting enzyme gene polymorphism in relation to HLA-DR in sarcoidosis. J Intern Med. (2002) 251:217-22. doi: 10.1046/j.1365-2796.2002.00946.x

50. Foley PJ, McGrath DS, Puscinska E, Petrek M, Kolek V, Drabek J, et al. Human leukocyte antigen-DRB1 position 11 residues are a common protective marker for sarcoidosis. Am J Respir Cell Mol Biol. (2001) 25:27277. doi: 10.1165/ajrcmb.25.3.4261

51. Kishore A, Petrek M. Next-generation sequencing based HLA typing: deciphering immunogenetic aspects of sarcoidosis. Front Genet. (2013) 9:503. doi: 10.3389/fgene.2018.00503

52. Fingerlin TE, Hamzeh N, Maier LA. Genetics of sarcoidosis. J Clin Chest Med. (2015) 36:569-84. doi: 10.1016/j.ccm.2015.08.002
53. Rossman MD, Thompson B, Frederick M, Iannuzzi MC, Rybicki BA, Pander JP, et al. HLA and environmental interactions in sarcoidosis. J Sarcoidosis Vasc Diffuse Lung Dis. (2008) 25:125-32.

54. Levin AM, Iannuzzi MC, Montgomery CG, Trudeau S, Datta I, McKeigue $\mathrm{P}$, et al. Association of ANXA11 genetic variation with sarcoidosis in African Americans and European Americans. Genes Immun. (2013) 14:138. doi: 10.1038/gene.2012.48

55. Wang P, Zheng SG. Regulatory T cells and B cells: implication on autoimmune diseases. Int J Clin Exp Pathol. (2013) 6:2668-74.

56. Sakthivel P, Brudera B. Mechanism of granuloma formation in sarcoidosis. Curr Opin Hematol. (2017) 24:59-65. doi: 10.1097/MOH.0000000000000301

57. Broos CE, van Nimwegen M, Hoogsteden HC, Hendriks R, Kool M, van Den Blink B. Granuloma formation in pulmonary sarcoidosis. J Front Immunol. (2013) 4:437. doi: 10.3389/fimmu.2013.00437

58. Georas SN, Chapman TJ, Crouser ED. Sarcoidosis and T-helper cells. Th1, Th17, or Th17.1? Am J Respir Crit Care Med. (2016) 193:1198200. doi: 10.1164/rccm.201512-2419ED

59. Reinert-Hartwall L, Honkanen J, Salo HM, Nieminen JK, Luopajärvi K, Härkönen $\mathrm{T}$, et al. Th1/Th17 plasticity is a marker of advanced $\beta$ cell autoimmunity and impaired glucose tolerance in humans. J Immunol. (2015) 194:68-75. doi: 10.4049/jimmunol.1401653

60. Huang $\mathrm{H}$, Zhiwei L, Jiang C, Liu J, Wang Y, Xu Z. Imbalance between Th17 and regulatory T-cells in sarcoidosis. J Mol Sci. (2013) 14:2146373. doi: 10.3390/ijms 141121463

61. Miyara M, Amoura Z, Parizot C, Badoual C, Dorgham K, Trad S, et al. The immune paradox of sarcoidosis and regulatory T cells. J Exp Med. (2006) 203:359-70. doi: 10.1084/jem.20050648

62. Wang P, Zheng SG. Regulatory T cells and B cells: implication on autoimmune diseases. Int J Clin Exp Pathol. (2013) 6:2668-74.

63. Rivera NV, Hagemann-Jensen M, Ferreira MAR, Kullber S, Eklund A, Martin NG, et al. Common variants of T-cells contribute differently to phenotypic variations in sarcoidosis. (2017) 7:5623. doi: 10.1038/s41598-017-0 5754-7

64. Petrelli A, van Wijk F. CD8(+) T cells in human autoimmune arthritis: the unusual suspects. Nat Rev Rheumatol. (2016) 12:421-8. doi: 10.1038/nrrheum.2016.74

65. Denic A, Wootla B, Rodriguez M. CD8 $(+)$ T cells in multiple sclerosis. Expert Opin Ther Targets. (2013) 17:1053-66. doi: 10.1517/14728222.2013.815726

66. Ahmadzai H, Cameron B, Chui J, Lloyd A, Wakefield D, Thomas P. Peripheral blood responses to specific antigens and CD28 in sarcoidosis. Respir Med. (2012) 106:701-9. doi: 10.1016/j.rmed.2012.01.012

67. Grunewald J, Eklund A. Role of CD4T cells in sarcoidosis. Prom Am Thorac Soc. (2007) 4:461-4. doi: 10.1513/pats.200606-130MS

68. Wahlström J, Dengjel J, Winquist O, Targoff I, Persson B, Duyar H, et al. Autoimmune $\mathrm{T}$ cell responses to antigenic peptides presented by bronchoalveolar lavage cell HLA-DR molecules in sarcoidosis. Clin Immunol. (2009) 133:353-63. doi: 10.1016/j.clim.2009.08.008

69. Tannenbaum H, Rocklin RE, Schur PH, Sheffer AL. Immune function in sarcoidosis studies on delayed hypersensitivity, B and T lymphocytes, serum immunoglobulins and serum. Clin Exp Immunol. (1976) 26:511-9.

70. Lee NS, Barber L, Akula SM, Sigounas G, Kataria YP, Arce S. Disturbed homeostasis and multiple signaling defects in the peripheral blood Bcell compartment of patients with severe chronic sarcoidosis. Clin Vaccine Immunol. (2011) 18:1306-16. doi: 10.1128/CVI.05118-11

71. Saussine A, Tazi A, Feuillet S, Rybojad M, Juillard C, Bergeron A, et al. Active chronic sarcoidosis is characterized by increased transitional blood B cells, increased Il-10-producing regulatory B cells and high BAFF levels. PLOS ONE. (2012) 7:e43588. doi: 10.1371/journal.pone.0043588

72. Belkhou A, Younsi R, Bouchti I, Hassani S. Rituximab as a treatment alternative in sarcoidosis. Joint Bone Spine. (2008) 75:511-2. doi: 10.1016/j.jbspin.2008.01.025

73. Bomprezzi R, Pati S, Chansakul C. Vollmer T. A case of neurosarcoidosis successfully treated with rituximab. Neurology. (2010) 75:568-70. doi: 10.1212/WNL.0b013e3181ec7ff9

74. Belhomme N, Jouneau S, Bouzilleâ G, Decaux O, Lederlin M, Guillot S, et al. Role of serum immunoglobulins for predicting sarcoidosis outcome: a cohort study. PLoS ONE. (2018) 13:e0193122. doi: 10.1371/journal.pone.01 93122 
75. Maddrey WC, Johns CJ, Boitnott JK, Iber FL. Sarcoidosis and chronic hepatic disease: a clinical and pathological study of 20 patients. J Med. (1970)49:37595. doi: 10.1097/00005792-197009000-00002

76. Fagan EA, Moore-Gillon JC, Turner-Warwick M. Multiorgan granulomas and mitochondrial antibodies. $N$ Eng J Med. (1983) 308:572-75. doi: 10.1056/NEJM198303103081006

77. Stanca CM, Fiel MI, Allina J, Caracta CF, Odin JA. Liver failure in an antimitochondrial antibody-positive patient with sarcoidosis: primary biliary cirrhosis or hepatic sarcoidosis? Semin Liver Dis. (2005) 25:36470. doi: 10.1055/s-2005-916327

78. Weinberg I, Vasiliev L, Gotsman I. Anti-dsDNA antibodies in sarcoidosis. Semin Arthritis Rheum. (2000) 29:32831. doi: 10.1016/S0049-0172(00)80019-0

79. Kobak S, Yilmaz H, Sever F, Duran A, Sen N. Anti-cyclic citrullinated peptide antibodies in patients with sarcoidosis. Sarcoidosis Vasc Diffuse Lung Dis. (2014) 31:206-10.

80. Kobak S, Yilmaz H, Sever F, Duran A, Sen N, Karaarslan A. The prevalence of antinuclear antibodies in patients with sarcoidosis. Autoimmune Dis. (2014) 2014:p351852. doi: 10.1155/2014/351852

81. Kinloch AJ, Kaiser Y, Wolfgeher D, Ai J, Eklund A, Clark Mr, et al. In situ humoral immunity to vimentin in HLA-DRB1*03+ patients with pulmonary sarcoidosis. Front Immunol. (2018) 9:1516. doi: 10.3389/fimmu.2018.01516

82. Shamaei M, Mortaz E, Pourabdollah M, Garssen J, Tabarsi P, Velayati A, et al. Evidence for M2 macrophages in granulomas from pulmonary sarcoidosis: a new aspect of macrophage heterogeneity. Hum Immunol. (2018) 79:639. doi: 10.1016/j.humimm.2017.10.009
83. Ciccarelli F, De Martinis M, Ginaldi L. An update on autoinflammatory diseases. Curr Med Chem. (2014) 21:2619. doi: 10.2174/09298673113206660303

84. Caso F, Galozzi P, Costa L, Sfriso P, Cantarini L, Punzi L. Autoinflammatory granulomatous diseases: from Blau syndrome and early-onset sarcoidosis to NOD2-mediated disease and Crohn's disease. RMD Open. (2015) 1:e000097. doi: 10.1136/rmdopen-2015-000097

85. Doria A, Zen M, Bettio S, Gatto M, Bassi N, Nalotto L, et al. Autoinflammation and autoimmunity: bridging the divide. Autoimmun Rev. (2012) 12:2230. doi: 10.1016/j.autrev.2012.07.018

86. Shoenfeld Y, Agmon-Levin N. 'ASIA'-autoimmune/inflammatory syndrome induced by adjuvants. J Autoimmun. (2011) 36:48. doi: 10.1016/j.jaut.2010.07.003

Conflict of Interest: The authors declare that the research was conducted in the absence of any commercial or financial relationships that could be construed as a potential conflict of interest.

Copyright (C) 2020 Starshinova, Malkova, Basantsova, Zinchenko, Kudryavtsev, Ershov, Soprun, Mayevskaya, Churilov and Yablonskiy. This is an open-access article distributed under the terms of the Creative Commons Attribution License (CC BY). The use, distribution or reproduction in other forums is permitted, provided the original author(s) and the copyright owner(s) are credited and that the original publication in this journal is cited, in accordance with accepted academic practice. No use, distribution or reproduction is permitted which does not comply with these terms. 